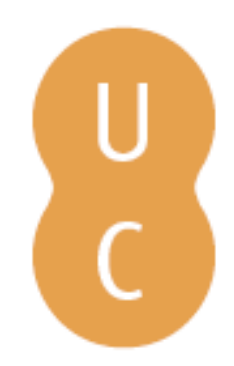

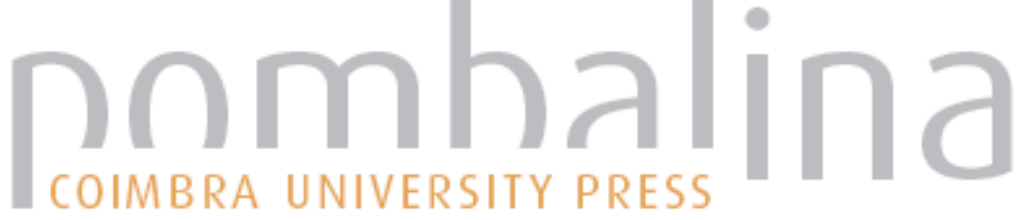

\section{O Aristóteles dos nossos tempos: Alberti a partir de Ribeiro Sanches}
Autor(es):
Providência, João Paulo
Publicado por: Imprensa da Universidade de Coimbra
URL persistente:
URI:http://hdl.handle.net/10316.2/36668
DOI:
DOI:http://dx.doi.org/10.14195/978-989-26-1015-3_6
Accessed : $\quad$ 26-Apr-2023 16:16:04

A navegação consulta e descarregamento dos títulos inseridos nas Bibliotecas Digitais UC Digitalis, UC Pombalina e UC Impactum, pressupõem a aceitação plena e sem reservas dos Termos e Condições de Uso destas Bibliotecas Digitais, disponíveis em https://digitalis.uc.pt/pt-pt/termos.

Conforme exposto nos referidos Termos e Condições de Uso, o descarregamento de títulos de acesso restrito requer uma licença válida de autorização devendo o utilizador aceder ao(s) documento(s) a partir de um endereço de IP da instituição detentora da supramencionada licença.

Ao utilizador é apenas permitido o descarregamento para uso pessoal, pelo que o emprego do(s) título(s) descarregado(s) para outro fim, designadamente comercial, carece de autorização do respetivo autor ou editor da obra.

Na medida em que todas as obras da UC Digitalis se encontram protegidas pelo Código do Direito de Autor e Direitos Conexos e demais legislação aplicável, toda a cópia, parcial ou total, deste documento, nos casos em que é legalmente admitida, deverá conter ou fazer-se acompanhar por este aviso.

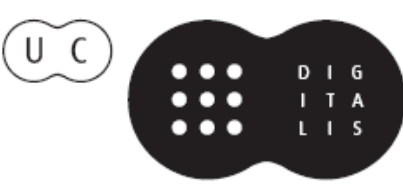


IMPRENSA DA

UNIVERSIDADE

DE COIMBRA

COIMBRA

UNIVERSITY

PRESS

\section{NA GÉNESE DAS RACIONALIDADES MODERNAS II}

Em torno de Alberti e do Humanismo

MÁRIO KRÜGER et alii

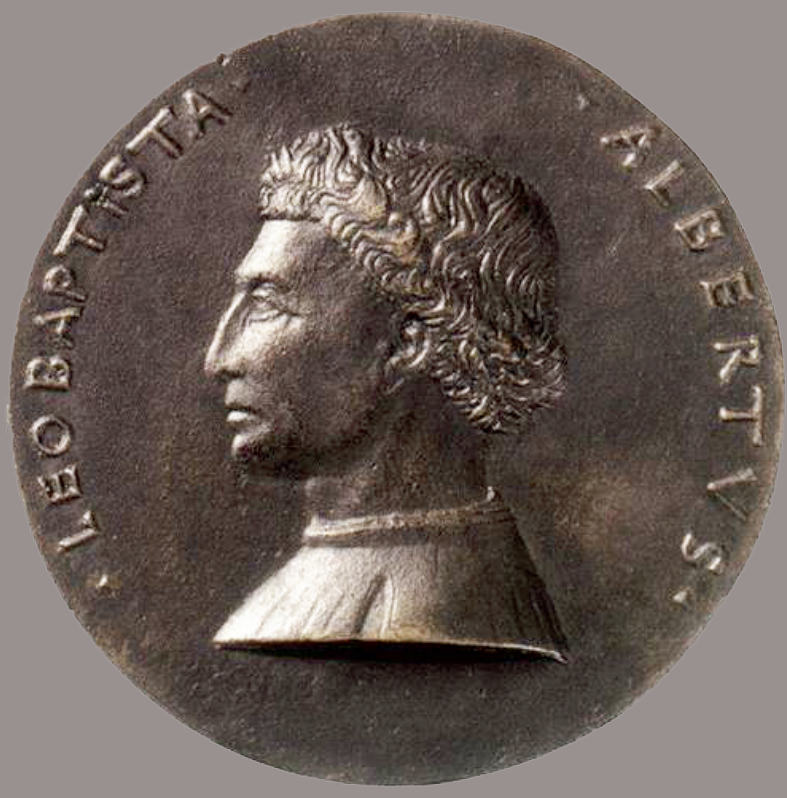




\section{O ARISTÓteles DOS NOSSOS TEMPOS - ALBERTI A PARTIR DE RIBEIRO SANCHES.}

João Paulo Providência

\section{Resumo}

A presente abordagem indaga sobre a presença do tratado Da Arte Edificatória de Leão Baptista Alberti no Tratado da Conservação da Saúde dos Povos, obra do médico iluminista António Nunes Ribeiro Sanches impressa em Paris em 1756. Situando-se entre as racionalidades do renascimento quinhentista e o iluminismo novecentista, o tratado de Sanches discorre sobre atmosferas e climas para determinar a Conservação da Saúde, antecipando a Higiene Pública. O recurso ao tratado de Alberti permite sublinhar a atenção aos contextos físicos no edificar, reforça as analogias cidade-arquitetura, arquitetura-medicina e arquitetura-corpo e instaura no início da época moderna uma conceção arquitetónica atenta ao seu papel social. António Nunes Ribeiro Sanches; Tratados de Saúde Pública; Analogia Medicina-Arquitetura.

\section{Résumé}

On propose une lecture sur la présence du traité De re aedificatoria de Leon Baptista Alberti sur le traité De La Conservation de la Santé des Peuples, travail du médecin portugais António Nunes Ribeiro Sanches imprimé à Paris en 1756. En se situant entre les rationalités de la Renaissance et les Lumières du XIX ${ }^{\mathrm{e}}$ siècle, le traité de Sanches part des atmosphères et des climats pour déterminer la préservation 
de la santé, en anticipant l'apparition de l'hygiène publique. L'utilisation du traité d'Alberti permet de souligner l'attention sur les paramètres physiques dans la construction, renforce les analogies ville-architecture, architecture-médecine et architecture-corps et établit une conception architecturale impliquée à son rôle social, aux commencements de l'époque moderne.

António Nunes Ribeiro Sanches; Traité de la Santé Publique; analogies architecture-médecine.

\section{Abstract}

This paper asks about the presence of the treaty De re aedificatoria by Leon Baptist Alberti in the Tratado da Conservação da Saúde dos Povos (Treaty for the Conservation of Health of People), a major work by the enlightened Portuguese medical doctor António Nunes Ribeiro Sanches printed in Paris in 1756. The treaty by Sanches situates itself between sixteenth century renaissance rationalities and nineteenth century enlightenment, pointing to the importance of climates and atmospheres on "the Conservation of Health" and therefore anticipating studies on Public Hygiene. Sanches quotations of Alberti's treaty allows him to highlight the importance of physical context in building, and reinforces the analogies city-architecture, architecture-medicine and architecture-body and fosters the social role of architecture in the beginnings of the modern age.

António Nunes Ribeiro Sanches; Public Health Treaties; Analogy Medicine-Architecture. 


\section{Sanches e os tratados de saúde pública}

O Tratado da Conservação da Saúde dos Povos de António Nunes Ribeiro Sanches (1699-1783), surge no panorama dos tratados de Saúde Pública, Polícia Higiénica ou Higiene - como será designada essa área de conhecimento a partir de finais do séc. XVIII e durante todo o séc. XIX - como um caso especial. Impresso em Paris em $1756^{142}$ tem sido visto como uma encomenda do governo português ao famoso médico, que residia naquela cidade desde 1747 . Essa encomenda, a par de uma outra sobre o Ensino da Medicina ${ }^{143}$, é realizada apressadamente após o terramoto de Lisboa de 1755 pelo Marquês de Pombal, temendo-se a profunda degradação da saúde pública resultante da catástrofe. Quer isto dizer, o Tratado de Sanches incide não apenas no elenco de regras de saúde pública tal como vinham sendo referidas pelo tratado Hipocrático Dos Ares, Águas, Lugares ${ }^{144}$, mas de uma forma propositiva na elaboração de regras de planeamento e edificação necessárias à reconstrução da cidade de Lisboa. A corroborar esta hipótese está o Apêndice incluído logo na primeira edição do Tratado, com o título "Considerações sobre os

142 ANTÓNIO NUNES RIBEIRO SANCHES, Tratado da Conservaçã̃ da Saude dos Povos: Obra util, e igualmente necessaria a os Magistrados, Capitaens Generais, Capitaens de Mar, e Guerra, Prelados, Abbadessas, Medicos, e Pays de Familias: com hum Appendix Consideraçoins sobre os Terremotos, com a noticia dos mais consideraveis, de que faz mençã̃ a Historia, e dos últimos que se sintirã̃ na Europa desde o I de novembro 1755., Em Paris, 1756. No presente trabalho foi utilizada a edição ANTÓNIO RIBEIRO SANCHES, Obras Completas, vol. II, Universitatis Conimbrigensis Studia Ac Regesta, Coimbra, Por Ordem da Universidade de Coimbra, 1966.

Segundo Maximino Correia (na introdução à edição da Universidade de Coimbra referida) há duas outras edições em português: uma, editada em Paris, 1756, e uma em Lisboa, 1575. Ainda segundo Correia, há uma edição em espanhol com tradução de D. Benito Bails (1730-1797), Madrid, 1781. Segundo Doria, há também uma edição italiana editada por Marcelo Sanches, que não consegui identificar: JOSÉ LUÍS DORIA, "Antonio Ribeiro Sanches - A portuguese doctor in 18th Century Europe", in Vesalius, VII, 1, 32, 2001.

143 ANTÓNIO NUNES RIBEIRO SANCHES, Método para Aprender e Estudar a Medicina, 1763, editada em ANTÓNIO RIBEIRO SANCHES, Obras Completas, vol. I, Universitatis Conimbrigensis Studia Ac Regesta, Coimbra, Por Ordem da Universidade de Coimbra, 1959.

${ }^{144}$ A edição consultada por Sanches é a de J. A. VAN DER LINDEN, Magni Hippocrates Coi opera omnia grece E latine, Lugduni Batavorum, 1665, cujo "De Aeribus, acquis \& locis" surge no $1^{\circ}$ volume (pág. 327-362) e que provavelmente conheceria da sua estadia com Boerhaave. Sobre as edições do tratado de Hipócrates, ver HiPPOCRATE, Oeuvres Complètes, Tome II 2eme partie, Airs-Eaux-Lieux, texte établi et traduit par Jacques Jouanna, Paris, Les Belles Lettres, 1996, 83-184. 
terramotos. Com a notícia dos mais consideráveis de que faz menção a História, e deste último que se sentiu na Europa no 1 de novembro de 1755".

No entanto o tratado tem ambições mais amplas do que apenas dar indicações sobre a conservação da saúde em situações de catástrofe; de fato, logo no prólogo Sanches remete para três destinatários preferenciais: os magistrados, os médicos e os arquitetos, ampliando as estritas recomendações técnicas na reconstrução da cidade.

A explícita referência aos magistrados permite inserir o tratado de Sanches na então recente tradição dos tratados de Polícia ${ }^{145}$. Polícia, como governo da Polis, é um termo introduzido na idade moderna através da leitura dos textos de Platão ("Politeia") e sobretudo Aristóteles, a "Constituição dos Atenienses", onde é descrita a eleição na cidade de Atenas de 10 comissários de polícia - 5 destinados ao porto de Pireo e outros 5 à cidade; a sua função de vigilância sobre as vias públicas (impedindo a sua obstrução com materiais de construção, a construção de varandas sobre a via pública, a abertura de janelas para o exterior ou a descarga de águas pluviais sobre a via) a par da vigilância sobre as atividades urbanas (vigiar o custo "dos flautistas, tocadores de lira e de cítara” para que não sejam alugados por mais do que duas dracmas), permite atribuir-lhe um significado de governação do espaço público, incluindo as atividades que nele decorrem e sua compatibilização com a vida quotidiana dos cidadãos. Que grande parte destas atividades se encontrassem altamente regulamentadas nas principais cidades europeias de inícios do séc. XVIII, é o que se pode depreender do exaustivo trabalho realizado por Nicolas de La Mare (1639-1723) sobre Paris, Traité de la police, Où l'on trouvera l'histoire de son établissement, les fonctions et les prérogatives de ses magistrats; toutes les loix et tous les réglemens qui la concernent: On y a joint une description historique et topographique

145 No Prólogo da tradução de D. Benito Bails do Tratado, Bails justifica o interesse que a obra lhe suscitou quando preparava o título "Policia da Cidade", no tomo nono dos seus Elementos de Matemática que trata da Arquitetura; ver MAXIMINO CORREIA, Introdução, in ANTÓNIO NUNES RIBEIRO SANCHES, Obras Completas, vol. II, Coimbra, 1966. A referência à Policia da cidade como sendo a vigilância do que se passa no seu governo é já citada por Hyeronimo del CASTillo Bovadilla, Politica para Corrigidores, Midina del Campo, 1608, 2 vols, obra também citada por Sanches. 
de Paris, \& buit Plans gravez, qui representent son ancien Etat, E ses divers accroissemens, avec un recueil de tous les statuts et réglemens des six corps des marchands, $\mathcal{E}$ de toutes les Communautez des Arts $\mathcal{E}$ Métiers..., Paris, J. et P. Cot, I vol. 1705, II vol. 1710, III vol. 1719, IV vol. (póstumo) 1738, editado entre 1705 e 1719, talvez o primeiro tratado de Polícia, que é aliás conhecido e citado por Sanches ${ }^{146}$. Esse tratado, embora ordenando as disposições legais sobre a segurança e tranquilidade pública (livro $7^{\circ}$ ), regista mais os costumes e legalidade das atividades urbanas de Paris do que a prevenção da saúde ${ }^{147}$.

De um ponto de vista médico, o Tratado de Sanches socorre-se tanto das fontes clássicas como dos estudos seus contemporâneos sobre atmosferas e climas, para definir uma "Medicina Política", "fundada nas leis da natureza, e nos conhecimentos [...] da boa Física”. Sanches procura fazer uma síntese estruturadora num campo de conhecimento que então despontava, antecipando o tratado de Johann Peter Frank (1779-1817) System einer vollständigen medicinischen Polizei, 9 vols., 1779-1819, ou as aulas de Jean Noël Hallé (1754-1822) no Collège de France em 1806, posteriormente editadas por Quérard em 1830 com o título Hygiène, ou l'art de conserver la santé. Esses estudos baseavam-se no tratado de Hipócrates, embora com recurso a edições anteriores à que repõe a ordem original do texto publicada por Émile Littré (1801-1881) em $1840^{148}$. Os tratados subsequentes de Higiene - e higiene é precisamente a "conservação da saúde" - tais como os de Michel Lévy (1809-1872) Traité d'hygiène publique et privée, 2 vols., 1844, Louis Fleury (1815-1872) Cours d’hygiéne, fait à la Faculté de Médicine de Paris, 1852, Louis Alfred Becquerel (1814-1862) Traité élémentaire d'hygiéne privee et publique, Paris, 1854, ou ainda o dicionário de

146 Sanches cita a edição de 1713 do Tratado, que é uma revisão da edição do vol. I editado em 1705, a propósito da obrigação "da limpeza necessária nas vilas e cidades para conservar o Ar puro", ou seja considerando a necessidade de manter as ruas da cidade limpas das imundícies, haveria "lei inviolável que cada morador tivesse limpa cada dia pela manhã a fronteira da sua casa”. Para corroborar esta legislação, cita de La Maré e Bovadilla (nota anterior).

147 Cf. http://data.bnf.fr/12450313/nicolas_de_la_mare_traite_de_la_police/

148 Cf. Hippocrate, Oeuvres Completes, 1996, cit. nota 3. 
Ambroise Tardieu (1818-1879) Dictionnaire d'bygiène publique et de salubrité, Paris, 1852-1862, baseiam-se na edição de Littré e já não referem as autoridades renascentistas incluindo Leão Baptista Alberti. O texto de Sanches, através de Hipócrates e Alberti, tomando do primeiro as prescrições do tratado Dos Ares, das águas, dos lugares, e do segundo a discursividade sobre o valor humanista da dignidade, estabelece a articulação entre as teorias climáticas e as teorias higienistas da contemporaneidade.

Sanches articula um conhecimento médico sobre o efeito das condições ou climas relativamente a saúde dos habitantes mas também à forma de melhorar essas condições, ou seja, a forma concreta como se deve conservar salubridade dos quatro elementos, obrigação dos Magistrados, e isto porque a saúde dos súbditos "mostra a necessidade que tem cada Estado de leis, e de regramentos para preservar-se de muitas doenças”. Evitar, a todo o custo, a poluição desses elementos primordiais, identificar de que forma são poluídos pelas atividades dos homens ou pela natureza, são assim os pressupostos para a Conservação da Saúde dos Povos, antecipando a proliferação de Topografias Médicas durante o séc. XIX. Para levar a cabo o seu estudo Sanches socorre-se, entre outros, da Física de Newton, explicando a origem dos ventos nos movimentos de ar decorrentes das variações de pressão e temperatura, e da Química de Boerhaave, explicando as qualidades das matérias.

Mas para além das atividades ou condições naturais, a conservação da saúde passa precisamente pela disposição do edificado, pelos traçados das cidades ou pela organização dos edifícios. A pertinência da arquitetura no tratado de Sanches é reforçada pela utilidade aos que pretendem edificar novas cidades "nos dilatados domínios de Portugal", utilidade reforçada pelas extensas referências à conservação da saúde nos navios e no exército, e justificando a sua edição em Português; as anotações sobre a saúde nos exércitos não será alheia às suas atividades como médico do exército, na Rússia.

Uma particularidade do tratado de Sanches está precisamente no cruzamento entre saúde, climas, cidades e arquiteturas, fato primeiramente assinalado pelo académico de Madrid D. Benito Bails nos seus 
Elementos de Matemática, em 1781, já referido por Maximino Correia ${ }^{149}$. O tratado pretende remediar um problema de formação dos arquitetos, "Fundaram-se as Escolas de Arquitetura Civil e Militar, mas não vemos que os Arquitetos instruídos nelas, façam caso da Física Geral na prática destas artes. Aprendem com perfeição como deve ser edificada uma cidade, uma praça, um templo, ou outro qualquer edifício público com toda a majestade, distribuição, e ornato, mas não vemos praticadas as boas regras, que contribuem à Conservação da Saúde”.

Outra particularidade refere-se à presença de Alberti no tratado, referências que não ocorrem nem no tratado de De La Maré nem nos tratados posteriores, de inícios do séc. $\mathrm{XIX}^{150}$. Sabendo que a cultura arquitetónica de Sanches inclui os textos de Vignola e Scamozzi, para além de O Engenheiro Português de Manuel de Azevedo Fortes (1660-1749), questiona-se o recurso a Alberti, sobretudo considerando a importância que, quer as racionalidades de $A$ ideia de Arquitetura Universal de Vincenzo Scamozzi, quer o amplamente divulgado Tratado das Cinco Ordens de Giacommo Vignola poderiam ter no espírito esclarecido de Sanches.

O interesse de Sanches pela Conservação da Saúde é também decorrente da sua vida profissional. A permanência de Ribeiro Sanches na Rússia entre 1731 e 1747, depois de ter estudado com Boerhaave em Leiden entre 1728 e $1731^{151}$, constitui a base da sua prática profissional: em 1733 é nomeado Médico de S. Petersburgo, em 1734 é empossado membro da Chancelaria de Medicina, e em 1735 é nomeado Médico do Exército, permanecendo nesse cargo durante 6 anos, ano em que é nomeado pela Imperatriz Médico do Corpo de Cadetes. Ainda em 1740 é nomeado Médico da Corte Russa, mas com a revolução de 1742 , que

149 Cf. a introdução de Maximino Correia em ANTÓNIO NUNES RIBEIRO SANCHES, Obras Completas, vol. II, Universitatis Conimbrigensis Studia Ac Regesta, Coimbra, Por Ordem da Universidade de Coimbra, 1966.

150 Talvez por isso, para alguns autores, o Tratado de Sanches surge como o percursor dos grandes tratados de Higiene, e não como uma revisão do tratado de De La Mare, que no fundo é apenas uma compilação da legislação francesa e sobretudo da cidade de Paris, sobre o controlo higiénico no seu funcionamento.

151 Na biografia de Sanches por Andry, deduz-se que tendo partido em 1731 para a Rússia e considerando que terá estudado 3 anos com Boerhaave, Sanches terá permanecido em Leiden de 1728 a 1731. 
coloca no trono russo Elisabete Petrowna, Sanches apercebe-se da dificuldade da sua posição e prepara a sua saída da Rússia. Em 1747 passa por Berlim e chega a Paris onde se estabelece. Em 1750 publica um trabalho sobre a doença venérea, em francês, trabalho que o consagra no meio médico parisiense. Em 1753 escreve uma Dissertação sobre as paixões da alma, obra em português e que será em parte incluída na voz "Affections de l'âme" incluída na Encyclopédie Méthodique, Médicine, 1784, e a partir de 1754 anota pensamentos sobre o ensino da Medicina - tema que vinha abordando com a tradução em 1722 dos estatutos morais do Colégio de Médicos de Londres e que culminarão com aconselhamentos sobre a organização desse ensino tanto em Portugal como na Rússia (Método para aprender..., Paris, 1763). A publicação do Tratado da Conservação da Saúde, publicado em 1756, permite-lhe tratar de um conjunto de assuntos que vinha investigando e que não são alheios à sua experiência como Médico militar na Rússia ${ }^{152}$.

\section{Sanches e a arquitetura: analogia entre medicina e arquitetura}

Uma das observações que atravessam o Tratado é a formação dos Médicos, posteriormente elaborada no "Método para aprender...". Logo no Prólogo refere: "poderia pretender o Leitor que indicasse neste Tratado, o methodo de estudar a Medicina, e como deviaõ os Medicos, e os Chirurgioens aprendela nas Escolas, e Universidades", depois de ter advertido, tomando uma citação de Hipócrates, que a arte médica é como a arte de navegar pois "nesta a theoria se aprende no mesmo tempo que se adqure a practica”. A crítica à formação médica (em Portugal, mas não exclusivamente), é articulada com a ausência de um ensino para a Conservação da Saúde dos Povos, considerando que a proliferação de "Collegios, Escolas, Academias, e Universidades" desde o Século XVI na Europa não contribuiu para essa

152 Não é apenas a experiência de médico mas também a sua observação dos cuidados de saúde populares na Rússia que merecem a sua etnografia antropológica; a incursão que o texto faz sobre os banhos de vapor tanto russos quanto turcos, são objeto da sua atenção. 
formação. Assim, Sanches coloca no Renascimento europeu os inícios de um ideal de formação universitária, não deixando de apontar falhas no ensino do que atualmente designamos como interdisciplinaridade.

É precisamente a analogia entre o ensino da medicina e da arquitetura que é referida numa carta dirigida a Joaquim Pedro de Abreu em 1760, onde compara a formação almejada para o médico com a formação de um arquiteto competente, demonstrando um amplo conhecimento da tratadística arquitetónica pelo recurso a Vitrúvio, Vignola ou Scammozi.

Como se pode depreender tanto da carta a Joaquim Pedro de Abreu como do texto Sur la culture des Sciences et des Beaux Arts en Russie ${ }^{153}$, o interesse de Sanches pela arquitetura é primeiramente de caráter pedagógico - a arquitetura surge ou inserida num ideal de formação humanista mais alargado, e cujas bases são para Sanches a racionalidade de Newton, ou como modelo de um pensamento racional necessário às reformas do ensino universitário, e sobretudo do ensino da medicina.

De fato, depois de condenar a falta de formação dos médicos em Portugal e fazer o elogio de um ensino experimental, Sanches faz uma analogia entre a aprendizagem e prática da medicina e da arquitetura. Crítica feroz a um ensino baseado nos efeitos e não nas causas, ou nas aparências e resultados e não na estruturação interna e progressiva, considera que ensino da medicina é um edifício sem fundações: "Como aprendemos a Medicina, e como a praticamos em Portugal nos primeiros anos da nossa prática” toma o exemplo da construção de um edifício sem alicerces - "ombreiras sem medidas, abobadas sem andaimes proporcionados" levam a um edifício em ruína iminente, "sem risco", que terá de ser desmantelado e começar-se de novo a edificar, "aprendendo pela experiência". Mas contrariamente ao médico, "o Arquiteto e o Engenheiro, instruído nas regras das artes, munido de instrumentos de que sabe usar, executa da primeira vez". E prossegue dizendo que o Arquiteto e o Engenheiro sabem explicar Vitrúvio, Vignola e Scamozzi

153 DAVID WILlemse, António Nunes Ribeiro Sanches - élève de Boerhaave et son importance pour la Russie, Janus suppl. Vol 6, 1966. Willemse transcreve o texto, que aliás se encontra na Biblioteca Pública Municipal de Braga, como refere. 
"da cadeira", e o segundo, De Vauban e St Remy, "Porque sem Geometria prática, Mecânica, e muitas partes da Física, e conhecimento de muitas artes não pode haver Arquiteto, nem Engenheiro."

Assim haveria de ser com o ensino da Medicina, baseada em "Newton, o grande Isaac Newton [...] o único Arquiteto da Física Geral, e experimental, como o foi da Medicina, o Príncipe dela o socorro da humanidade, Hermano Boerhaave."

Mas como é construído um conhecimento para "executar da primeira vez"? Através de um método experimental que distingue "as observações no que concordam", e "separando-as do que discordam", tanto para a Física como fez Newton, como para a Medicina como fez Boerhaave, que "ajuntou com um trabalho incrível todas as operações, e produções do corpo são, e enfermo, observou no que concordavam, e no que se diferenciavam, combinando, e separando tudo que conservava, ou destruía o corpo humano, formou aquelas imortais obras que nos deixou."

Assim, a Medicina deve ser aprendida "por regras, e por método tão científico, como requer a sua inteligência, perfeição, e utilidade pública, para obrigar os Mestres ensina-lo; o que se estende não somente da Medicina, mas ainda de todas as ciências humanas, que se ensinam ou devem ensinar na Universidade."

Sanches conclui a sua analogia arquitetura-medicina com o exemplo de um arquiteto bem instruído ("um Arquiteto de Superior instrução nas Matemáticas, Mecânica, Física, e mais artes relativas à sua ciência”) que pretende edificar uma Basílica, com os materiais que havia no local: "Estou vendo que este Arquiteto mandou separar uns dos outros; aqui mandava separar as pedras molares para os alicerces; lá os mármores para as colunas; da outra parte as traves, e as madeiras para os andaimes, e os metais para as ataduras, e ornamentos; media depois o terreno, compunha o seu risco, media depois as pedras para as colunas, e arquitraves, e as abóbadas e mandava conforme o talho assentar cada pedra, e cada metal em seu lugar; de tal modo, que ficando todos separados, mas unidos pela arte vinham a compor um belo e majestoso edifício, onda a comodidade, a facilidade, agrado, gradação e proporção faziam sentir a harmonia à primeira vista." 


\section{Alberti, o Aristóteles dos nossos tempos}

No trecho citado é fácil reconhecer Alberti: "os metais para as ataduras", o procedimento analítico, o risco prévio à execução, a execução de acordo com o risco, o assentamento das peças no lugar destinado, a composição como resultado da assemblagem dos materiais de tal forma que ficando "todos separados" se apresentam "unidos pela arte", a supremacia da "harmonia" (dificuldade de tradução da concinnitas albertiana?). No entanto, e apesar de na carta a Abreu Sanches demonstrar os seus conhecimentos e até apreço pela arquitetura, permanece um problema de fundo, a saber: por que é que Sanches se socorre do Tratado de Alberti, considerando quer a sua difícil divulgação em Portugal (em parte por estar escrito em Latim e não haver edição em Português, em parte porque é um tratado sem ilustrações), quer a redundância das prescrições higiénicas de edificação com outras fontes, como Hipócrates ou Vitrúvio?

A estes fatores acresce que as edições do tratado de Alberti, nesse momento, não estão na 'moda'. No gráfico que Mário Krüger edita em "A Receção da Arte Edificatória"154, Fig. 4, é assinalada isoladamente a edição em Inglês de 1726, e a única edição anterior que não em Latim é a edição em Espanhol de 1582, seguindo-se posteriormente ao Tratado de Sanches as edições em Italiano de 1784, de novo em Espanhol de 1797, informação concordante com o elenco de edições referidas em Rykwert, Leach e Tavernor ${ }^{155}$. Ou seja, o tratado de Alberti quando dele Sanches se socorre já não é best-seller, já havia passado a 'febre' das edições dos séculos XVI e XVII; e embora haja uma edição em Inglês em 1726, a edição anterior havia sido impressa 174 anos antes e em Espanhol. Acresce que Sanches não refere nenhuma dessas edições, socorrendo-se da edição em latim de 1541, ou seja a terceira edição, impressa em Estrasburgo ou Argentorati, segundo Rykwert. Quer isto dizer que se socorre de uma fonte na edição original em Latim e impressa há mais de duzentos anos.

${ }^{154}$ LEON BATTISTA ALBERTI, Da Arte Edificatória, trad. de A. M. do Espírito Santo, introd., notas e revisão disciplinar de M. J. Teixeira Krüger, Lisboa, Fundação Calouste Gulbenkian, 2011, p. 87.

155 LEON BATTISTA ALBERTI, De re aedificatoria. On the art of building in ten books., trad. Joseph Rykwert, Neil Leach, e Robert Tavernor. Cambridge, Mass., MIT Press, 1988. 
Para Sanches a construção do conhecimento não deve ir atrás da última 'moda', do último livro, da replicação das razões circunstanciais; refere, a este propósito, que terá aprendido com Boerhaave a relativizar as novidades na produção do conhecimento, e a colocar os avanços de conhecimento de acordo com a fundamentação, prevalecendo o raciocínio sobre a novidade. Neste sentido, o texto de Alberti com a sua sólida estruturação, parece não apenas responder aos anseios de Sanches como até, talvez, corresponda a uma vontade de fundamentação de conhecimento em medicina que procurava, e a utilização do texto original em latim, com a sua típica construção gramatical, responde à racionalidade desses anseios.

Uma segunda razão tem a ver com os cuidados construtivos necessários à conservação da pureza do ar nas casas, referidos no cap. XX da Conservação da Saúde. Esses cuidados remetem para a qualidade dos elementos construtivos e sobretudo para a necessária secagem da construção antes da ocupação. Como refere, se os arquitetos "estivessem instruídos nos importantes avisos que nos deixou Leão-Baptista Alberti satisfariam a utilidade, e a elegância da Arquitetura” ao mesmo tempo que conservariam a saúde, para que não se verifique o provérbio português "casa feita, pega morta".

Mas talvez a razão maior seja que, tal como Sanches refere, Alberti é uma autoridade, quer dizer um autor que instaura uma discursividade ${ }^{156}$. Neste sentido pode pensar-se na formação jurídica de Alberti, numa certa natureza normativa do seu tratado, e até numa aspiração a uma sociedade fundada no valor humanista da dignidade. A propósito "do sumo cuidado que se deve ter na prisões para purificar o ar delas, e renova-lo cada dia”, no cap. XIX, Sanches socorre-se das considerações de Alberti sobre a prisão no livro V, capítulo 13, do Da Arte Edificatória: a divisão da prisão em três "lugares diferentes" em conformidade com os crimes que os detidos expiam, e do "dever de tratar o prisioneiro com humanidade, e comodidades tais da vida, que possam conservar forças, e o vigor, que há-de empregar um dia no serviço comum"; são estas considerações que

156 Sobre a instauração da discursividade, Cf. MICHEL FOUCAULT, "Qu'est-ce qu'un auter?"(1969), in MICHEl FOUCAUlT, Dits et Écrits, 1954-1975, vol. I, Paris, Gallimard, 2001. Sobre Alberti como instaurador de discursividade, ver FRANÇOISE CHOAY, La Règle et le Modèle: Sur la théorie de l'architecture et de l'urbanisme, Paris, Seuil,1980. 
levam Sanches a qualificar Alberti de "o Aristóteles dos nossos tempos", talvez o maior elogio que Sanches pudesse fazer ao arquiteto florentino.

Françoise Choay, em La Règle et le Modèle, chama justamente a atenção para a importância que Aristóteles tem no pensamento de Alberti, e mais concretamente vê no Da Arte Edificatória uma estrutura de exposição que se inicia pela forma, conceção ou lineamenta (livro I), expõe a matéria (livro II), para depois discorrer sobre a construção como síntese entre forma e matéria, ou opus (livro III); de resto, a estrutura do tratado reproduziria as três características da arquitetura em três níveis - a necessidade, a que correspondem os três primeiros livros, a comodidade nos livros IV e V, e o prazer, a que corresponderiam os livros VI, VII, VIII e IX.

Neste sentido, talvez o maior reflexo da apropriação aristotélica no discurso de Alberti que Sanches incorpora esteja na analogia corpo-edifício, tão cara a Alberti, e que pela aproximação ao discurso anatómico sobre o corpo surge de fácil apropriação em Sanches. É na Poética que Aristóteles estabelece a analogia corpo-discurso, ou antes, animal-argumento: "Além disso, uma coisa bela - seja um animal seja toda uma ação - sendo composto de algumas partes, precisará não somente de as ter ordenadas, mas também de ter uma dimensão que não seja ao acaso: a beleza reside na dimensão e na ordem e, por isso, um animal belo não poderá ser nem demasiado pequeno [...] nem demasiado grande [...]". Segundo Choay ${ }^{157}$, Alberti vai mesmo mais longe que Aristóteles na identificação entre edifício e corpo considerando que o edifício é um corpo vivo, já que concebido por lineamenta (dar forma na ideia e em espírito) ou seja, aquilo que se poderia chamar o espírito (ingenio) que 'anima' a matéria.

Uma interpretação do tratado de Alberti centrada na analogia corpo-edifício, ou na analogia medicina-arquitetura, permite avançar uma hipótese para a compreensão da sua estrutura: uma vez que o tratado de Alberti se inicia com a problemática dos sítios sadios para a edificação (no livro I), ou como diria Sanches com a conservação dos elementos, é natural que conclua (no livro $\mathrm{X}$ ) com a correção de assentamentos

157 FRANÇOISE CHOAY, La Règle et le Modèle: Sur la théorie de l'architecture et de l'urbanisme, Paris, Seuil,1980: 89-90. 
urbanos cujos lugares foram mal escolhidos - ou pela fraca defesa que propiciam ou pela ausência de água, ou pelo mau clima em que se implantam. Essas correções são da ordem das terapias médicas numa cidade-corpo que não atenta à conservação da sua saúde.

Pelo seu lado, a estrutura do Tratado da Conservação da Saúde organiza-se em duas partes e inclui um apêndice. Na primeira, do cap. I ( $D a$ Natureza do Ar) ao cap. XIV (Das qualidades das águas saudáveis, e como se devem entreter os poços, os rios, e os portos de mar para a Conservação da Saúde) considera especificamente a conservação dos elementos, nomeadamente o ar e a água. Numa segunda parte, que se pode considerar de aplicação e resolução de problemas práticos, trata especificamente da conservação desses elementos nos edifícios e instituições de maior concentração de habitantes: Igrejas (cap. XV), Conventos (cap. XVI), Hospitais (cap. XVII e XVIII), Prisões (cap. XIX), Casas (cap. XX), Casernas (e a conservação da saúde dos soldados, do cap. XXI a XXVI) e Navios (cap. XXVII a XXI). Atendendo às referências explícitas ou citações, pode-se dizer que Sanches se socorre de Alberti porque ao discorrer no cap. IX sobre "os sítios mais sadios para fundar cidades" ou no cap. XII sobre "como devem ser os edifícios para a Conservação da Saúde" no "interior das cidades", encontra em Alberti indicações precisas ou disposições sobre esses assuntos. Embora não referida explicitamente, está implícito ao discurso de Sanches a apropriação do conceito de Regio de Alberti, assim como uma abordagem que parte do geral, regio, area, para o particular, dispositio, mura, coberta apertum. A Regio e circunstâncias influentes farão o seu caminho em toda a literatura Higienista. As reiteradas referências a Alberti e ao seu tratado permitem a Sanches instaurar nos inícios da Arquitetura na Época Moderna o discurso sobre a Conservação da Saúde e o papel da edificação - da casa à cidade - nesse propósito político; permitem também a construção de um discurso interdisciplinar que se socorre das ciências naturais e do estudo dos climas para definir um propósito médico. Permite, por fim, pelas implicações na conceção arquitetónica implícitas à analogia corpo-arquitetura, reclamar um outro papel para a Arquitetura, mais atento à sua função social e às consequências da sua produção para a Saúde Pública. 